\title{
Towards Responsible Dissent and the Rise of Transformational Futures
}

\begin{abstract}
Richard A. Slaughter
Abstract

The paper suggests that well-known global trends lead toward futures that no-one would choose and that we should seek to avoid. Naive affluent populations do not respond effectively, in part because they take refuge in strategies of avoidance, especially those available through modern technology. Futures Studies (FS) plays an ambiguous role because it is used both in ideologically regressive and progressive ways. The need for dissenting futures arises from such considerations. In fact FS embraces perspectives and methodologies which enable dissent. It then becomes possible to re-vision the foundations of human futures, including those termed 'transformational'. This is a valid task for futures practitioners. From this viewpoint dissent becomes a positive driver of adaptive social change.
\end{abstract}

\section{The road to hell is paved}

The dominant trends that are well established within the global system do not lead to a world of peace, prosperity and plenty. They lead to a world that is devastated and diminished in nearly every respect. It is the road to hell: a world that is mined out, polluted, denuded of other life forms and compromised beyond all hope of salvage or repair. How can this be stated with such apparent confidence?

For several decades now the evidence has been accumulating. It is there for anyone to see, hear and understand. The evidence has been collected by large numbers of scientists, researchers, scholars, writers and others. It has been written up in countless papers, articles and books. ${ }^{1}$ It has been debated at length in many conferences and convocations of the wise. The evidence has been the subject of tv documentaries. It has been woven into films, novels, school curricula and no doubt other forms of media as well. Who knows how many column inches of evidence exist in newspapers or data banks, in archives and libraries around the world?

But humanity has created for itself some remarkable defence mechanisms, some of which have been taken up, exploited and reinforced by those in charge of large organisations and state instrumentalities. Yet it is a mistake to imagine that the effective blinding of entire populations is primarily some sort of conspiracy or cover up. This is a secondary explanation, at best. More centrally, present ways of life, modes of social and economic organisation, continue on their selfdestructive path because humans have construed their world in particular ways for millennia. They are not about to change deeply ingrained habits of perception without confronting powerfully persuasive reasons why they should do so.

Unfortunately, social experiences of the kind that would be needed are themselves fairly drastic. So humanity drifts along in a kind of business-as-usual daze, largely unaware that the time of its proud and uncaring dominance are numbered unless it understands, and comes fully to grips with, what I call the 'civilisational challenge'. The challenge is to clearly comprehend the historical predicament humanity is now in and to respond to it, not superficially, but with clarity, depth and commitment. But comprehension is limited when the worldview, the 'cultural software' available is, in certain respects, defective and if people in their daily lives have constant recourse to all the forms of denial, evasion and unreality that the market ensures are plentifully available. ${ }^{2}$ 
So the metaphorical 'road to hell' has an outer and an inner aspect. The outer is made up of the processes of global deterioration that are reflected and reported in the ways mentioned above. The inner dimension lies in the self-understandings of people and in the active principles that operate in the organisations and societies they have created. The web of social and economic life that prevails on the planet at the turn of the millennium is one that was constructed painstakingly over many generations and largely in very different conditions to those that now exist. It is a huge achievement. But the frame-breaking proposition before us is that humanity must either forward in some fairly major ways - or risk falling back into a much more primitive state.

The road to hell may be paved with good intentions, but we need much more than these to learn our way ahead with diligence and skill.

\section{The ambiguity of Futures Studies}

One of the main psychodynamic forces that created the 20th century field of Futures Studies (FS) is the realisation that modernisation, development, technology and so forth have progressively created a whole new arena of options for humanity, some of which are welcome, some of which are not. In other words, the future stopped being seen as a natural and unproblematic unfolding of forces and structures in the past and present. Instead, it took on a new significance, linking human perceptions of possible future states with actions and decisions progressively taken in the advancing present.

This is the promise of FS: that it gives to humanity the tools by which to choose future states worth creating and to put in train the means by which to achieve them.

But 'humanity' is not a monolithic whole. It is a deeply divided and incredibly diverse family of beings with profoundly unequal access to wealth, power and autonomy. Under these conditions, FS has been taken up most readily by those whose present is secure - or at least relatively so. Moreover, within those privileged enclaves, FS has been applied most fully and consistently by those whom, as de Jouvenel pointed out some decades ago, have specific interests in 'colonising' the future for their own purposes. Thus, despite many progressive organisations and initiatives in FS, the promise that FS was a gain for humanity has, to some extent, been subverted by its appropriation by powerful groups. That this is not mere rhetoric is shown by the effective development and wide use of futures methodologies within transnational corporations. By contrast, governments remain wedded to short-term pragmatic thinking, and those running education systems remain blissfully unaware of the methodological and symbolic options that FS offers them.

All entities are shaped and conditioned by the social relations in which they are located. Put FS in a school and you get simple tools and concepts to enable certain key shifts of perception. Put FS in corporations and you get sophisticated scenarios for enhanced planning and marketing. The failure of many progressive organisations, education systems and, indeed, universities, to take up and use FS in a range of ways means that the very tools, the means to achieve the necessary changes of selfperception and practice upon which our collective future now hangs, are still not widely available and hence not widely used. The ambiguity of mainstream FS is that at the level of broad social needs, ie., that of securing a future worth having for our descendants, it has so far failed to have a significant impact.

\section{The emergence of dissenting futures}

The rationale for dissenting futures arises from the above. If FS practitioners merely accept the standard presuppositions of conventional politics, governance, economics, wealth-creation, land- 
use, science policy, technology development and so on, they merely reinforce the grounds of our historical dilemma in which various elites play out their games of dominance, greed and power within shrinking arenas of freedom. On the other hand, dissenting futures will not only explore options that lie beyond the purview of the mainstream, they will also employ and encourage other values, other frameworks of meaning, other ways of knowing.

To be in a position of dissent from existing administrative bodies, power structures and practical arrangements - such as earning a living - is to occupy a social role that is challenging to say the least. It means that one is sometimes likely to be perceived in fairly negative terms, eg., as disloyal, critical, a source of embarrassment - overall, someone to be avoided. The dissenting futurist is therefore likely to face a double penalty: one for being a futurist in the first place; another for taking dissenting positions within FS. This means that one is not likely to be offered easy access to highlypaid work, career advancement or material wealth.

However, it should be clear that there is now, as never before, a number of reasons why dissent can be seen as one of the responsibilities of a futurist. To summarise, first, the mere extension of existing structures and trends puts entire populations at risk. Second, the identification of FS with existing centres of power greatly reduces its social and cultural value, its ability to innovate more widely. Third, positive dissent can reveal the grounds of new personal and social options. It is in this latter respect that the positive pay-off of a dissenting stance really lies. Given the clearly vulnerable role of those who elect to take this position within FS, it is much to be regretted that so few universities have yet seen fit to apply their supposed interest in maintaining intellectual autonomy to these contexts.

\section{What methods and perspectives are available?}

There are at least four areas from which the tools and methods of dissenting futures can be derived. They are: critical futures studies, multicultural futures work, macrohistory and design/visioning approaches. Each is briefly outlined below. Others can, and certainly will, be added over time.

\section{Critical futures studies}

This emerged from the perceived shortcomings of the largely empiricist American tradition and its unconscious reliance upon unquestioned (and hence invisible) socio-cultural presuppositions. In this context 'critical' does not simply mean 'to criticise'. A more accurate formulation would be: 'looking more deeply'. What this means in practice is a process of 'probing beneath the surface' to consider futures problems at a range of levels right down to the framing of worldviews and worldview commitments. Careful attention to phenomena at these levels provides a much richer account of social reality, social change, social potential than could ever be derived from more the more superficial accounts available in pop futurism. So, for example, in a critical futures approach, topics such as 'health', 'wealth', 'growth' and 'development' are subjected to fairly thorough treatment such that processes of socio-cultural framing, editing, exclusion etc are revealed. When such phenomena emerge into human consciousness they become visible and can be dealt with clearly. Hence, critical FS provides tools of understanding that can help to reveal why things are the way they are and, to some extent, how they can be changed. For example the notion of a 'wise culture' can be used to contrast with, and problematise, industrial culture, thereby opening out new conceptual and practical spaces. The latter provides the grounding for a vast range of social innovations. Hence, although there is a necessary abstraction in some aspects of critical futures work, the outputs can be intensely practical. ${ }^{3}$ 
This does not simply refer to a lateral process of expanding the boundaries of FS in space to include other cultures, important as this is. Rather, it refers to the bringing of a new kind of depth to futures work as a result of engaging with 'the other' in substance, not merely in surface features. For example, Ashis Nandy suggests that 'for me, futures studies is basically a game of dissenting visions. It is an attempt to widen human choices: by reconceptualising political, social and cultural ends; by identifying emerging or previously ignored social pathologies that have to be understood, contained or transcended; and by linking up the fates of different polities and societies through envisioning their common fears and hopes.' ${ }^{4}$ Again, Sohail Inayatullah writes, 'real futures ... are perhaps those that cause cognitive dissonance, that do not make sense to the immediate - not because they are nonsensical but because we do not have the epistemological frames to comprehend them.' 5 In other words, multicultural futures work is partly about bringing new voices into the futures conversation. But more profoundly it is about exploring new (or maybe old) arenas of cultural and epistemological possibility. Thus, in such ways, the futures enterprise is both deepened and universalised.

\section{Futures and macrohistory}

One of the criticisms of FS in general was that its grounding in related fields was not well mapped. However, this criticism now carries less force than it did (except with the uninformed). For in fact a number of areas of related study have emerged in recent years. One of these is macrohistory, the search for large patterns in the past, present and futures of humanity. This brings into play an openness to the great theorists of the past and present who sought a larger canvass upon which to view human affairs, much as FS itself does. 6

So access to macrohistory provides us with models, stages, concepts for coming to grips with the long view. Properly understood, it also frees us of intellectual and cultural parochialism, meaning that we can begin to more consciously situate our efforts in a wider frame and in a conscious appreciation of some of the larger dynamics of history. In such ways, macrohistory is a natural ally not only of dissenting futures, but of FS in general.

\section{Designing and visioning processes}

Having travelled the roads of abstraction and depth, of other cultures and other ways of knowing, of the dynamics of macrohistory, there then arises the task of refreshing our visions of divergent futures and then translating these visions into socially-useful forms through designs for social and practical innovations. I mentioned the example of a 'wise culture' above. What would it be like? How would it respond to a vastly enhanced internet, to the emerging genetic revolution, to nanotechnology? How would business and commerce change if it altered some of the present guiding presuppositions and substituted others that derived from 'the economics of permanence'? How would education change if the present generation of soulless bureaucrats were replaced with people who had learned how to balance and reconcile both the inner and outer worlds? What if governance became imbued with transpersonal awareness, respect for life and the rights of future generations? Questions of this kind can be explored in depth in futures visioning workshops. 7

We should never forget that the human brain/mind system embraces an arena which is far larger than that which is physically present. It can range at will through distant pasts and explore distant futures with equal ease. It can look reflexively upon the pre-given axioms that it inherited from a particular culture, substitute different ones and explore the consequences. Human beings are selfconstituting beings and reflexivity is a natural talent for them. When it is supplied with the rich 
materials outlined above then visioning and design become powerful avenues for the constitution of human futures on grounds very different from those which now prevail.

\section{Re-visioning the foundations of viable human futures}

At present the key drivers of change in the world emerge from the still relatively primitive stages of human and social development such as are expressed in: technical dynamism coupled with scientism, materialism, commercial exploitation (profit-driven organisations such as the transnationals, banks etc.), nationalism (the military-industrial complex), colonialism, greed, short-term thinking, ego, fear of death and defects in the Western industrial worldview - particularly shortterm thinking and the hegemony of instrumental rationality. We should not overlook the fact that Western industrial culture certainly contains some desirable features (eg. ideals of social justice, technical skill, high material standards of living). But, overall, it has become fundamentally antilife, having lost sight of 'the inner world' during the industrialisation process. It read out of its world picture key areas such as myth, ritual, connectedness, spirituality and the numinous.

However, there are other options available that help us to break away from the industrial fantasy, re-connecting us to each other and the earth. In part, this involves re-valuing native cultures, ending exploitation and embracing 'the other'. ${ }^{8}$ I also want to encourage people to feel symbolically powerful, ie., capable of re-defining their reality and actively responding to their own deeper needs, those of their children and of future generations. I therefore want to see the growth of foresight and wisdom in all the world's cultures. I want to see them implemented in every organisation and built up to the social and global levels. I also want to see morality and ethics become much more widely understood and applied. Otherwise it is entirely possible that technology or eco-catastrophe will overrun us, much as some writers have depicted. On the other hand, with the tools of critical futures studies and the wider frame provided by writers such as Hesse and Wilber, we can explore a different set of cultural assumptions that could lead in a very different direction. ${ }^{9}$ What are some of the possibilities that could be re-negotiated at a deeper level?

We could do worse than to explore the notion that the Western worldview is, to a worrying extent, defective and hence provides us with a thin, instrumental, view of the world. Next, we can be clear about the fact that many, if not most, of the dominant political and economic powers in the world are on the wrong track insofar as they are perpetuating destructive and unsustainable views, practices and systems. Third, there are significant arenas of human experience that have been marginalised or overlooked by Western institutions, some of which can be recovered. Fourth, we can explore the notion that our much-vaunted 'cutting edge' technologies may actually be derivative and secondary in terms of what matters most to people. Fifth, we can imagine that the present ideology of material growth could replaced by an ethic of 'enoughness' or 'voluntary simplicity' and that a stewardship ethic replaced the current consumerist ethos. Finally we can draw on all the above to speculate - in a coherent and disciplined way - about how things might be different if we were to consciously re-design the Western worldview by retiring defective components and replacing them with consciously-chosen equivalents. 10

This kind of deeply grounded and extended 'thought experiment' is surprisingly rare. But even this brief overview suggests that the range of possibility for re-visioning the near-term future is much, much broader than even futures specialists may realise. It follows that, unlike some of my colleagues, I don't believe that the human race is merely a transitional species that should make way for so-called 'intelligent' machines. In this view, it is a species capable of endless selftransformation, vertical (qualitative) growth and development. 
As we reach the end of the 20th century and contemplate the 21 st, viable futures for humankind cannot be created from pre-industrial, industrial, or post-industrial models (though elements from each will be retained). We should not therefore uncritically carry over existing cultural commitments from this era to the next. Rather, we need to let go of some earlier commitments and consciously take up others. We need grounded visions, designs if you will, of a world that has experienced a recovery of vision, meaning and purpose; one that has moved beyond the disastrous conceits of industrialism - particularly the obsession with material growth, the subjugation of nature and the marginalisation of non-Western cultures. Such a world is likely to be fundamentally a postmaterialist one which embraces stewardship and the needs of future generations. Intrinsic value would become more dominant than use-, or exchange value. Science and technology would be reigned in and subjected to higher-order imperatives. This would be a materially stable but infinitely more subtle, interconnected and many-layered world.

Hence it is my view that dissenting futures can be unambiguously positive and, moreover, they can be brought within imaginative, intellectual - and thus practical - reach. The focussing concept of a wise culture places the pursuit of wisdom above raw technical power. ${ }^{11}$ Such a culture is farsighted and imbued throughout with transpersonal awareness. To our great cost, a sense of this 'transformational' future is not easy to find in industrialised cultures or their dominant institutions but it can certainly be derived from carefully reflecting on the sources drawn upon here. ${ }^{12}$ The route from here (the slide toward destruction) to there (a future worth living in) is through the growth of human awareness across the planet and the implementation of a host of future-saving, future-creating, structures and processes. Most of these already exist in culturally marginalised forms. But they are also metaphorical seeds which await the opportunity to grow. A powerful key to their mainstream emergence is an advanced futures discourse which can critique and re-shape existing agendas. Such a discourse can be developed through speculative writing, futures studies and associated fields. ${ }^{13}$ Overall, the goal is to work toward the creation of social foresight and the steady emergence of societies and cultures that are not merely past-driven, but responsive to the emerging near-term future context. ${ }^{14}$

\section{Conclusion}

Dissent is an intelligent response to the prospect of a world lurching toward a future that no sane person can contemplate with equanimity. It is a positive attempt to draw attention to the implications of the dysfunctions now embedded in our social, economic and technical systems. It most certainly not a call to revolution but, rather, to participation and far-sighted, deep design in every area of our lives and work.

Positive dissent is not one thing, but many. It is critique, design, vision. It is access to unofficial knowledge. It is engagement with 'the other' and the in-depth exploration of non-standard scenarios, visions and outlooks. It is epistemological play in the fields of culture and time.

\section{References}

1. Brown, L. (ed), State of the World 1998, London, Earthscan.

2. Mitroff, I. \& Bennis, W. The Unreality Industry, 1989, Carol Publishing Group, New York.

3. Slaughter, R. The Foresight Principle, London, Adamantine, 1995.

4. Nandy, A. Can Futures Studies Create Opportunities for Dissent? WFSF Futures Bulletin, 22, 3, Sep. 1996, p 1. 
5. Inayatullah, S. Listening to Non-Western Perspectives, in Hicks, D. \& Slaughter, R. (eds), World Yearbook of Education 1998: Futures Education, London, Kogan Page, 1998, p 59.

6. Galtung, G. \& Inayatullah, S. Macrohistory and Macrohistorians: Perspectives on Individual, Social and Civilisational Change, Westport, CT, Praeger, 1997.

7. Boulding, E. The Challenge of Imaging Peace in Wartime, in, Slaughter, R. (ed), The Knowledge Base of Futures Studies, Vol. 2: Organisations, Practices, Products, Futures Study Centre, Melbourne, 1996, pp 223-229.

8. Sardar, Z. Other Futures: Non-Western Futures in Futures Studies, in Slaughter, R. (ed), The Knowledge Base of Futures Studies, Vol. 1: Foundations, Futures Study Centre, Melbourne, 1996, pp 217-233.

9. Hesse, H. Siddhartha, New Directions, New York, 1951, p 32; Wilber, K. Sex, Ecology, Spirituality: the Spirit of Evolution, Shambhala, Boston, 1995 and Wilber, K. A Brief History of Everything, Hill of Content, Melbourne, 1996, p 336.

10. Slaughter, R. Critical Futures Study and Worldview Design, Proceedings of the Xll World Conference of the World Futures Studies Federation, Turku School of Economics, Finland, 1992. 11. Polak, F. The Image of the Future, translated and abridged by Elise Boulding, New York, Oceana Press, 1961.

12. Op cit note 9 .

13. Slaughter, R. (ed) The Knowledge Base of Futures Studies, Vols. 1-3, Futures Study Centre, Melbourne, 1996.

14. Slaughter, R. Futures Studies: from individual to social capacity, Futures, Vol 28, 8, 1996, pp 751-762.

Note: An edited version of this paper was published in Futures 31, 1999 pp. 147-154. 